\title{
Ectopic parathyroid adenoma in thymus
}

\begin{abstract}
The atypical location of the adenoma of the parathyroid gland occurs not frequently. The most common place of the ectopia is the thymus. Many diagnostic methods have to be used to establish the point of the abnormal locality of the parathyroid gland adenoma. Among them are USG, CT, MRI and technetium $99 \mathrm{~m}$ scan. We reported on the young woman with the unusual clinical case - the two parathyroid gland adenomas, one of which was located in thymus. The second adenoma was found only after primary surgical elimination of the first one, and absence of the hormone level normalization. It was located in thymus. The second surgery procedure was performed-thoracoscopic thymectomia. The patient completely recovered.
\end{abstract}

Keywords: adenoma of the parathyroid gland, ectopia, thymus

\author{
Volume 3 Issue 4 - 2017
}

Ihor Hipp, ${ }^{1,2}$ Lyubomir Khrupovich, ${ }^{2}$ Lesja Hrygoriv, ${ }^{2}$ Yuriy Mylyan, ${ }^{1,2}$ Roman Gulei ${ }^{2}$ 'Danylo Halycky Lviv National Medical University, Ukraine ${ }^{2}$ Department of thoracic surgery, Lviv State Oncological Regional Therapeutical and Diagnostic Centre, Ukraine

Correspondence: Ihor Hipp, Danylo Halycky Lviv National Medical University, Hashek str. 2a, 7903I, Lviv, Ukraine, Tel +380672558453, Email ihorhipp@gmail.com

Received: June 09, 2017 | Published: July 13, 2017

\section{Introduction}

Adenoma of the parathyroid gland is a frequent cause of hyperparathyroidism. Ectopic location of the parathyroid glad occurs in $6-16 \% .{ }^{1}$ The most common location of ectopia is thymus, the next retroesophageal region and thyroid gland. There are many diagnostic methods to trace the parathyroid adenoma. These are-USG, CT, MRI and technetium $99 \mathrm{~m}$ scan. We report on a 35year old woman with two adenomas of the parathyroid gland one of them was located in thymys.

\section{Case report}

The 35year old woman was admitted to the division of thoracic surgery diagnosed with the-Ectopic parathyroid gland adenoma in thymus. Special symptoms were not revealed. The level of parathyroid

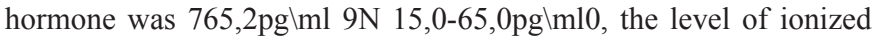
serum calcium was $1,82 \mathrm{mmol} \backslash 1(1,16-1,32 \mathrm{mmol} \backslash \mathrm{l})$ Analyses were performed in Synevo laboratory (www.synevo.ua)

Three months before the adenoma of right parathyroid gland was discovered by USG and the increased level of parathyroid hormone$615,8 \mathrm{pg} / \mathrm{ml}$, ionized calcium-2,06mmol $/ 1$. The patient had been operated in the division of head and neck tumors. The right lobe of thyroid gland and the parathyroid enlarged gland were eliminated. The histological examination showed adenoma of parathyroid gland.

The patient was operated first time in other hospital. There is a lack of the information of the reason of the performing the right lobe thyroid gland resection. The second adenoma was not detected in previous examinations. The technetium $99 \mathrm{~m}$ scan was not performed. But instead of the decreasing level of the parathyroid hormone after two weeks following surgery the control had shown the increasing of the hormone level. Consequently the USG, CT, MRI and technetium $99 \mathrm{~m}$ scan were performed.

The USG showed only post surgery condition- right thyroid lobe was eliminated, left parathyroid glands without pathology. CT-the ectopic parathyroid gland in thymus Figure 1. MRI-in the tissue of non involute thymus the knot formation $15 \times 10 \times 14 \mathrm{~mm}$ is visualized which is suspected as ectopic parathyroid gland Figure 2. According to the technetium $99 \mathrm{~m}$ scan - the signs of ectopic parathyroid gland in the left side of thymus are present Figure 3.

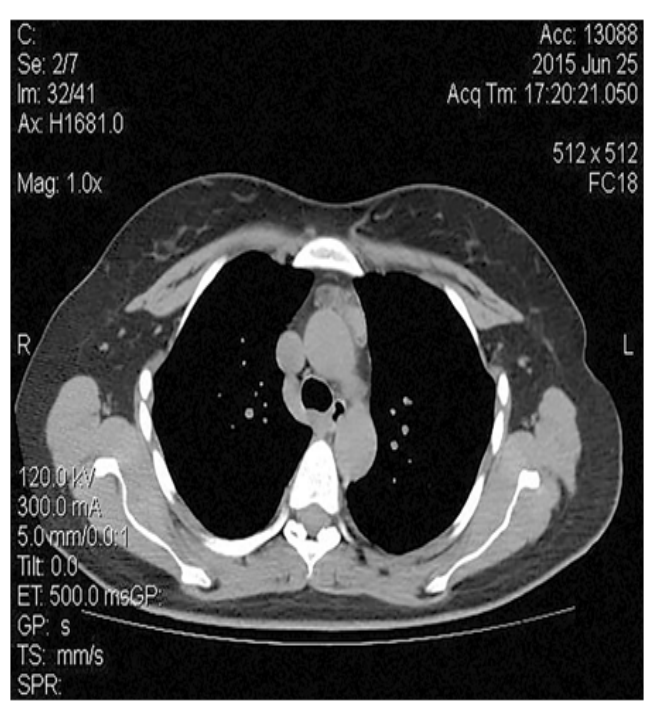

Figure I The CT image of the parathyroid adenoma in thymus.

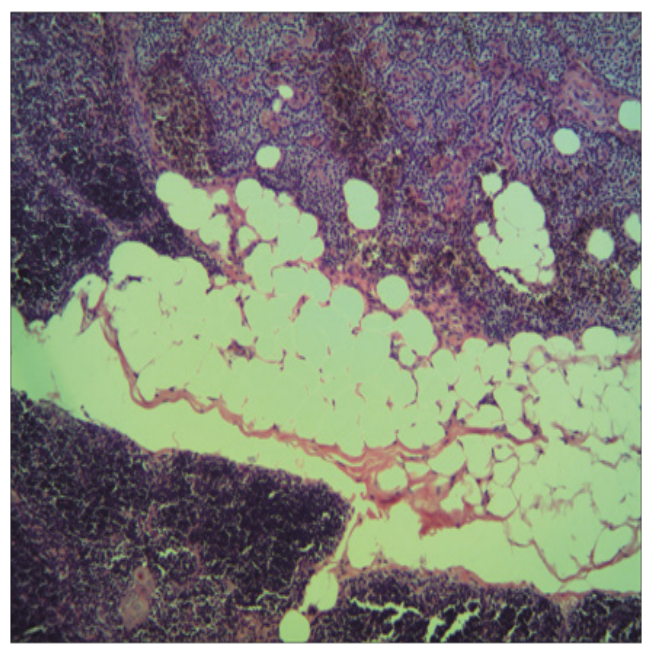

Figure 2 The $M R I$ image of the parathyroid adenoma.

The left side videothoracoscopic thymectomy was performed. The histological examination showed the parathyroid gland adenoma in 
the tissue of thymus Figure 4. During the postoperative period no complications were presented. The level of parathyroid hormone one week after surgery decreased to $89,2 \mathrm{pg} / \mathrm{ml}$

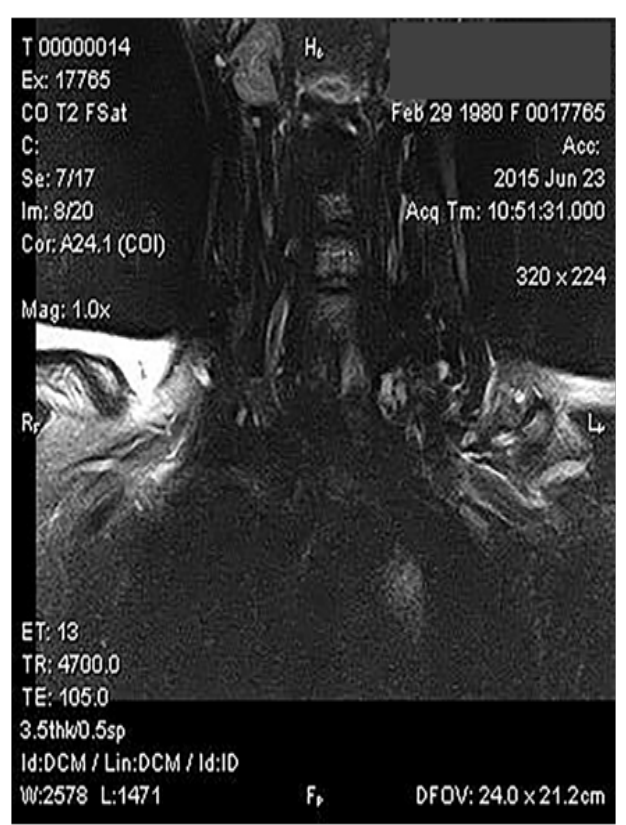

Figure 3 The technetium scan of the parathyroid adenoma.

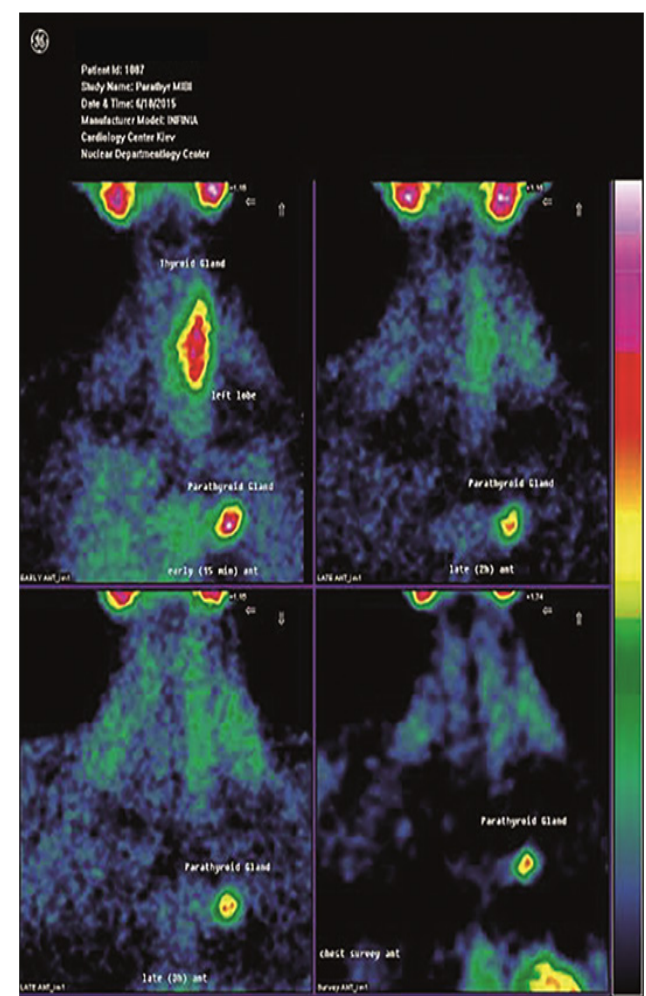

Figure 4 Histological findings:

Macro: Fragment of faty tissue $4 \times 4 \times 2 \mathrm{~cm}$ with well circumscribed incapsulated round to ovoid nodule, tan in color soft and fleshy in consistency, $1.5 \times 1.5 \mathrm{~cm}$ in measurment.

Micro: The tumor cosist of proliferates of "light" cells with optical empty cytoplasm and rounded nuclei with congested chromatin, and rare conspicous nucleus, which coprrespond to chief cells of parathyroid gland in solid and trabecular to follicular patterns; stroma rich vascularised with residual fat tissue. The histological picture correspond to chief cells adenoma of parathyroid gland, which sharply contrasted with surrounded thymus gland tissue with noticable Hassall's body.

\section{Discussion}

Primary hyperparathyroidism is more common among female then among male in the proportion 3 to 1 . It is mostly caused by solitary adenoma ( $80-85 \%$ ), double adenoma occurs in about $4 \%$ and multiple adenoma of parathyroid gland could be found in 10 to $15 \%$ of primary hyperparathyroidism. ${ }^{2}$ According all said patients should be examined accurately in order to reveal all pathological lesions. The technetium $99 \mathrm{~m}$ scan should be included to the examination plan as one of the high sensitive method. ${ }^{1-3}$ The combination of CT or MRI with the technetium $99 \mathrm{~m}$ scan can improve the diagnostic of the ectopic parathyroid adenoma with sensitivity and specificity $100 \%$.

The evaluation of the parathyroid adenoma during surgery is important. The frozen section or gamma probe can be used. ${ }^{5}$ But in case of ectopic adenoma the thin slice CT with contrast can be very helpful to localize the pathological lesion. ${ }^{6}$

There are many surgical technics to eliminate the ectopic parathyroid adenoma. Thoracotomy, sternotomy or endoscopic methods can be used. We performed the thoracoscopic technology as the less traumatic. The goal of the surgery was the elimination of the non involute thymus with the parathyroid adenoma. The surgery was performed very carefully to prevent injuring of the nervi frenici, and vessels. We used the electrosurgical instruments prepare the thymus. No complications occurred during surgery. The endoscopic surgical technology can be successful used in the treatment of the ectopic parathyroid gland in the thymus.

\section{Acknowledgements}

None.

\section{Conflict of interest}

Author declares that there is no conflict of interest.

\section{References}

1. Roy M, Mazeh H, Chen H, et al. Incidence and localization of ectopic parathyroid adenomas in previously unexplored patients. World J Surg. 2013;37(1):102-106.

2. Elaraj DM, Clark OH. Current status and treatment of primary hyperparathyroidism. Perm J. 2008;12(1):32-37.

3. Vijyakumar V, Anderson ME. Detection of ectopic parathyroid adenoma by early Tc-99m sestamibi imaging. Ann Nucl Med. 2005;19(2):157-159.

4. Zerizer I, Parsaï A, Win Z, et al. Anatomical and functional localizationof ectopic parathyroid adenomas: 6year institutional experience. $\mathrm{Nucl}$ Med Commun. 2011;32(6):496-502.

5. Soyer T, Karnak I, Tuncel M, et al. Results of intraoperative gamma probe survey and frozen section in surgical treatment of parathyroid adenoma in children. J pediatr Surg. 2016;51(9):1492-1495.

6. Panchani RA, Varma T, Goyal A, et al. A challenging case of an ectopic parathyroid adenoma. Indian J Endocrinol Metab. 2012;16(Suppl 2):408-410 